\title{
Sports Culture Research of Network Construction in University Physical
}

\section{Education}

\author{
Shuhua Guo \\ Yunnan Physical Education College of Qujing Normal University \\ Sjzpt_wyh@126.com
}

Keywords: sports culture, sports and cultural networks, Physical Education

\begin{abstract}
The network contains a history of sports, cultural education, cultural content and form of special means of expression. It is the sum of material and spiritual wealth of the people in the sports social activities which depend on network technology and information resources as a fulcrum sports network activity and creativity. Narrow network of sports culture is sports knowledge and sports information to the computer can recognize the code in the form of record, and the dissemination and exchange via computer to the Internet; broad network of sports culture is spread by network environment knowledge of sports information and sports generated a human culture. It is an extension of the human traditional sports culture, traditional sports and traditional sports ethics education and diverse show.
\end{abstract}

\section{Introduction}

In the university culture, the sports culture is very important, with its own unique characteristics, form and content. With the introduction of quality education, physical exercise, sports competitions and sports teaching universities have made considerable achievements; the university should not only focus on teaching students the intellectual, and should pay more attention to the body of teaching indoctrination, so that students in Chile balanced development of the body and become qualified successors of socialist construction. However, in today's highly competitive society, many universities still "re-teach wisdom, light and Education", sports and culture can not be placed in the same position with culture and education, so our college sports and cultural development of many deficiencies still exists.

\section{Superiority of Network background education}

Network teaching is a web technology support, making for student groups, teaching content. Content in the form is less rigid traditional teaching, vividly the teaching system, teaching content integration, through careful design, the teaching content through resource sharing and teaching materials to show up more easily arouse students' interest and curiosity . Professor content online education, teaching methods and control are based on the characteristics of the students developed to provide online education required by each of the learning environment, regardless of time limits for the practical significance of higher learning for different students, giving learners a great free space; online teaching can overcome the shortcomings of the traditional teaching of one-way traffic, the network platform for the interaction of teachers and students to enhance the operability of that interaction. At the same time, it is able to create learning for distant learners. Virtual teaching atmosphere for students to be able to solve the problem encountered in the study, improve learning efficiency. 


\section{Online education practical significance for higher education}

(1) The construction of the network environment is an important part of sports culture construction in college sports. Physical Education as a lifelong sports start-up phase, the development will lay the basis of everyone's life. The importance of college sports building is self-evident, and the network of sports culture in the student's education is more for its specificity. Physical education in schools is an emerging network of sports education in the form; it will have a profound impact.

(2) Network sports and cultural environment of the school sports teaching plays a role in the past. Build a network of sports and cultural environment in the network is teaching this information age came into being in promoting physical education in colleges and universities at the same time, the network will become the basis for future sports education reform, and promote the continuous development of sports education.

(3) Network sports and cultural environment promote the role of school physical education teaching management. Network sports culture is a part of network physical education to promote the development and progress of the campus network physical education. Meanwhile, not only the construction and development of physical culture and the network is an important research topic, but also in the creation of its own infinite value. Therefore, a correct understanding of network sports and cultural environment for the improvement of school education and promoting quality of education has an important significance.

\section{Problems existing in College Physical Education applications of Network Sports Culture}

The network sports culture used in teaching make full use of network resources, implementation of network teaching, survival and development should be the path of the 21st century modern teaching college sports. But there are still some problems in the implementation of specific aspects:

(1) The concept behind. While many schools connected to the Internet has been a long time, many physical education teachers to bring the Internet to the human society experience great changes and opportunities is not deep, failed to recognize the necessity and urgency of this work. So it should be fully emancipate the mind, changing concepts can be implemented faster and better network teaching.

(2) Underutilized. As the subject of physical education - students of sports information resources on the Internet utilization is too low, and even some students did not even know that you can find the data and information from the Internet, it is not to mention the problem of rational use of it.

(3) Lack of talent. Institutions of higher education sports department in a computer network with the talent of the relative lack of professional knowledge should speed up the training of personnel in this area with the introduction and strengthening personnel training in the post.

(4) Sports lack of learning and research software. Look at the current software market, sports disciplinary teaching and research software category rarely, which require us to specialized teachers in school sports in close contact with the computer network researchers, timely developed to meet the requirements of modern sports teaching software products as soon as possible for teaching and research.

\section{Measures to further deepen the culture of higher education in the construction of network sports}

(1) Do a good job teaching design, network technology and better services for the College Sports Online Courses.

Network sports and cultural institutions as a leading sports management and decision-making 
provides the basic information and scientific means, it makes students to be transformed from passive learning to active learning, to achieve the purpose of sports training innovative talents. However, the use of advanced teaching media, there is no change in teaching concepts, and advanced teaching facilities can be able to impart knowledge to play only as a tool. In order to optimize the teaching, learning effective, every learner must be instructional design.

(2) The expansion of network resources and vigorously develop the library.

Network instruction in Sports College needs to build a lot of resources in the library. Using computer network technology, teachers should create and demonstrate the use of factual, mood, demonstration, principles and sense of inquiry and other problems and situations; through their own development, strengthen exchanges and sharing ways to build multimedia, large capacity, open learning resource library and then build a learning environment and individual cooperative learning environment.

(3) Construction of campus sports culture distinctive website.

Campus Sports Culture refers to a specific campus sports culture presented, which is a network of sports culture important organic components. It is based on the student, extra-curricular sports activities as the main content, and the main campus space to campus spirit as a group culture main characteristic. The establishment of this culture as the core content type sports website, not just for effective media network sports and cultural infiltration, and training objectives with schools, school discipline ethos and lifestyle content is closely related to maximize teaching and learning the two-way interaction.

\section{Improve physical education teachers' literacy network information}

P.E. teachers should promptly establish the correct network sports and cultural awareness

Only physical education teachers recognize that IT will bring physical education a positive role, and the use of new technologies and new tools are confident in the teaching process, then the advantages of the Internet may have been fully utilized; only the physical education teachers for the new techniques and new tools to show interest and curiosity, is it possible to simultaneously guide the students to learn new knowledge, to teach students to select the information they need in a timely manner to establish the correct network.

P.E. teachers should constantly update their knowledge

Putting the Internet in PE teaching, teachers and students are in the same environment. In terms of the environment is unfamiliar to students, for teachers in terms of equally unfamiliar and challenging environment. Therefore, physical education teachers must continue to learn and update their knowledge, changing concepts of education. Particular emphasis on the use of computer networks to improve practical level, to develop their own capacity to design courseware and online operations capabilities.

\section{Conclusion}

As the subject of physical education - teachers and students in terms of strengthening the construction of a network of sports culture, on the one hand, to optimize the college sports network information platform to enhance information literacy education college physical education teachers, to improve their knowledge and skills structure to help them understand and the use of modern information tools, so that they can be effective for sports information resources " column " and " format", and use of information science theories and methods to develop teaching college sports network. On the other hand, stepped up training and improving the skills of college students use 
sports information, sports network to promote its effective use of information resources, gradually increase the awareness and application of college sports information initiative to help students master the use of new technologies and new ways of learning resources promote students' health , mental health and social adaptation of harmony and unity in order to achieve the ultimate goal of physical education.

\section{References}

[1] National Institute of Physical universal textbook writing team of School Physical Education. [M] Beijing: People's Sports Publishing House, 1991.

[2] Yun Xuerong, Cultural Construction of Campus Sports Analysis [D] Chengdu: Sichuan University, 2004.

[3] Zhu Li, Network Information Technology in Competitive Sports [J] Sichuan Sports Science, 2004, Section 2.

[4] Deng Xinghua, Current Situation and Countermeasures of sports information network dissemination [J]. Sports and Science, 2002, Volume 36, No. 1.

[5] Yang Jing, The use of multimedia and network technology to the Athletics Teaching. [J]. Chengdu Institute of Education, 2004, Volume 18, No. 12.

[6] Cai Lei, Computer Technology and Sports [J] Shandong Education and Research, 2001, 11. 